\title{
Preparation and Characterization of Carboxymethylchitosan
}

\author{
Fernanda R. de Abreu, Sérgio P. Campana-Filho \\ Instituto de Química de São Carlos, USP
}

\begin{abstract}
Chitosan was reacted with monochloroacetic acid at room temperature for different reaction times $(3 \mathrm{~h}, 5 \mathrm{~h}, 7 \mathrm{~h}$ and 10h) and employing two chitosan/monochloroacetic acid molar ratios (1:4.3 or 1:8.6). The carboxymethylation of chitosan was confirmed by ${ }^{1} \mathrm{H}$ NMR and ${ }^{13} \mathrm{C}$ NMR spectroscopy. The carboxymethylchitosans had average degrees of substitution ranging from 0.52 to 1.44 as determined by potentiometric and conductimetric analysis. The occurrence of $\mathrm{N}, \mathrm{O}$-carboxymethylation was also observed in all cases.
\end{abstract}

Keywords: Chitosan, carboxymethylchitosan, degree of substitution, characterization.

\section{Introduction}

Chitin, a polysaccharide usually isolated from the carapaces of marines animals such as crabs and shrimps, is a homopolymer composed of 2-acetamide-2-deoxy-Dglucopyranose units linked by $\beta(1 \rightarrow 4)$ bonds (Figure 1a). Chitosan is a copolymer of 2-amino-2-deoxy-D-glucopyranose and 2-acetamide-2-deoxy-D-glucopyranose also linked by $\beta(1 \rightarrow 4)$ bonds (Figure $1 \mathrm{~b}$ ) which is commercially available from the deacetylation of chitin ${ }^{[1,2]}$.

The industrial production of chitin/chitosan is growing in the latter years due to the great stimulus of the food processing industry for the utilization of its refuses, mainly shells of shrimps and crabs, and mainly to the properties of these polymers, such as biocompatibility, biodegradability and their ability to interact with different substances, such as heavy metals and pesticides ${ }^{[1,3]}$. Thus, chitin, chitosan and their derivatives prepared by chemical modifications have been used in many applications in the food industry, in cosmetic formulations, for medical and pharmaceutical applications, in the agriculture and in the wastewater treatment for the removal of metallic ions and humic acids ${ }^{[4]}$.

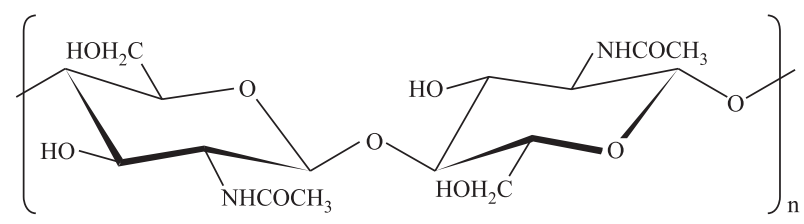

a)

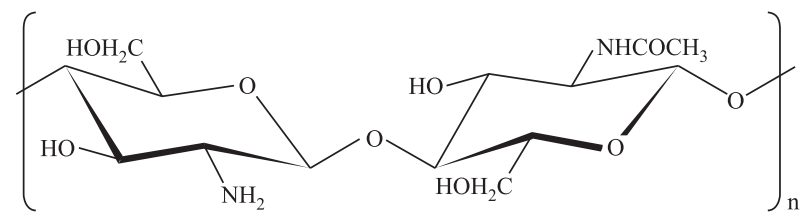

b)

Figure 1. Schematic representation of the primary structure of chitin (a) and chitosan (b).
The amino groups of chitosan are weak bases which are predominantly protonated when $\mathrm{pH}<\mathrm{pK}_{\mathrm{o}} \approx 6.5$, leading to the solubilization of the polymer only in acid dilute solutions. However, the poor solubility of chitosan when $\mathrm{pH}>6.5$ is a serious drawback in many of its potential applications. Thus, the preparation of chitosan derivatives has been envisaged to overcome its limited solubility in aqueous media. Such an adequate chemical modification results, for instance, when the carboxymethylation of chitosan is carried out since carboxymethylchitosan is soluble in a wide range of $\mathrm{pH}^{[5,6]}$.

The antimicrobial activity of chitosan and carboxymethylchitosan may allow their application in agriculture for inhibiting the growth of fungi and bacteria during storage of fruits and vegetables. Such an application is specially interesting for the food industry since these polymers have low toxicity and because they are adequate to oral administration ${ }^{[7]}$. The limited solubility of chitosan to acid media also limits its use as an antimicrobial agent in the food industry since the low $\mathrm{pH}$ may favor deleterious reactions on the food, altering its color and flavor. However, as carboxymethylchitosan is soluble in a wider range of $\mathrm{pH}$ its application in this field does not suffer from this drawback ${ }^{[8]}$. The affinity of chitin, chitosan and derivatives to metal ions, such as $\mathrm{Cu}, \mathrm{Cd}, \mathrm{Pb}, \mathrm{Ni}, \mathrm{Co}$ e $\mathrm{Ca}$, has also been reported ${ }^{[9]}$, allowing their application for the treatment of industrial effluents. Also in this case the carboxymethylchitosan presents some advantages as compared to chitosan for complexing more efficiently $\mathrm{Cu}^{+2}$ and presenting affinity for a larger number of ions ${ }^{[10]}$. Other important applications of carboxymethylchitosan include the medical and pharmaceutical areas, mainly for the controlled release of drugs, orthopedic devices and tissue adhesion $^{[11]}$.

The reactive sites for the carboxymethylation of chitosan are the amino and hydroxyl groups present in its chains. According to the literature ${ }^{[12]}$, the choice of the appropriate reaction conditions and reagents allows the preparation of

Autor para Correspondência: Sergio P. Campana-Filho, Instituto de Química de São Carlos, USP, Avenida Trabalhador São-carlense, 400, Caixa Postal 780, CEP:13560-970, São Carlos, SP. E-mail: scampana@iqsc.usp.br 
$\mathrm{N}-, \mathrm{O}-, \mathrm{N}, \mathrm{O}-$ or N,N-carboxymethylchitosan. Thus, O-carboxymethylchitosan is predominantly obtained when the reaction is carried out at room temperature, in suspension of isopropanol/water and in the presence of monochloroacetic acid and sodium hydroxide. However, this reaction yields Nand N,O-carboxymethylchitosan if it is carried out at higher temperatures ${ }^{[13]}$. On the other hand, the N-carboxymethylchitosan may be prepared by the reaction of chitosan with glyoxylic acid followed by reduction with sodium cyanoborohydride, the degree of substitution of the derivative being determined by the reaction stoichiometry and the characteristics of the parent chitosan ${ }^{(14)}$.

The properties and applications of carboxymethychitosan are strongly dependent on its structural characteristics, mainly the average degree of substitution and the locus, amino or hydroxyl groups, of the carboxymethylation. Thus, the aim of this work is to evaluate the effect of the reaction conditions, essentially the molar ratios chitosan/monochloroacetic acid and the reaction time, on the characteristics of carboxymethylchitosan.

\section{Experimental}

\section{Purification of Chitosan}

Commercial chitosan (Fluka), named as sample Q, was purified on neutral form after dissolution in dilute acetic acid, filtration and precipitation upon addition of ammonium hydroxide. The purified sample was milled in a domestic blender and the fraction composed by particles having an average diameter lower than $125 \mu \mathrm{m}$ was then used for the carboxymethylation.

\section{Preparation and Purification of Carboxymethylchitosan}

Following the procedure described for the carboxymethylation of cellulose ${ }^{[15]}$, purified chitosan (3g) was dispersed in $65 \mathrm{~mL}$ of isopropanol. After 20 minutes of magnetic stirring at room temperature, $20.4 \mathrm{~g}$ of aqueous $\mathrm{NaOH}(40 \%)$ and $14.4 \mathrm{~g}$ of monochloroacetic acid/isopropanol solution $(1: 1 \mathrm{~m} / \mathrm{m})$ were added to the suspension. The reaction proceeded to the desired time at room temperature and the solid product was then filtered, suspended in $150 \mathrm{~mL}$ of methanol and neutralized with glacial acetic acid. The product was extensively washed with $80 \%$ ethanol and dried at room temperature. Different carboxymethylchitosan samples were prepared by employing different reaction times (3h, $5 \mathrm{~h}, 7 \mathrm{~h}, 10 \mathrm{~h})$ and molar ratios of chitosan/monochloroacetic acid (1:4.3 or 1:8.6). By employing the molar ratio $1: 4.3$ and carrying out the carboxymethylation reaction for $3 \mathrm{~h}, 5 \mathrm{~h}, 7 \mathrm{~h}$ and $10 \mathrm{~h}$ resulted in the samples $\mathrm{QC}_{3}, \mathrm{QC}_{5}, \mathrm{QC}_{7}$ and $\mathrm{QC}_{10}$, respectively. The carboxymethylchitosan samples $\mathrm{QC}_{7 \mathrm{E}}$ and $\mathrm{QC}_{10 \mathrm{E}}$ were obtained when the reactions were extended for $7 \mathrm{~h}$ and $10 \mathrm{~h}$, respectively, employing the molar ratio 1:8.6.

For the purification of these derivatives, $1.5 \mathrm{~g}$ of the sample were dissolved in $1.5 \mathrm{~L}$ of aqueous solution of $0.1 \mathrm{M} \mathrm{NaCl}$. The resulting solution was filtered and the carbox- ymethylchitosan was precipitated upon addition of absolute ethanol. Then, the carboxymethylchitosan was washed with ethanol/water mixtures of increasing ethanol content $(75 \%$, $80 \%$ and $90 \%$ ) and finally with absolute ethanol.

\section{NMR Spectroscopy}

The ${ }^{1} \mathrm{H}$ NMR and ${ }^{13} \mathrm{C}$ NMR spectra of chitosan and carboxymethylchitosans were acquired at $80{ }^{\circ} \mathrm{C}$ by using a $200 \mathrm{MHz}$ spectrometer (Bruker AC200). For acquiring the ${ }^{1} \mathrm{H}$ NMR spectra of chitosan and carboxymethylchitosans their solutions were prepared at concentrations $10 \mathrm{mg} / \mathrm{mL}$ and $20 \mathrm{mg} / \mathrm{mL}$, respectively. Both polymers were dissolved in $\mathrm{D}_{2} \mathrm{O} / \mathrm{HCl}(100 / 1 \mathrm{v} / \mathrm{v})$ for ${ }^{1} \mathrm{H}$ NMR but solutions of carboxymethylchitosan in $\mathrm{D}_{2} \mathrm{O}$ were used for ${ }^{13} \mathrm{C}$ NMR.

\section{Conductimetric and Potenciometric Analysis}

The titrations of the aqueous solutions of chitosan and carboxymethylchitosan $\left(\mathrm{C}_{\mathrm{p}} \cong 1 \mathrm{~g} / \mathrm{L}\right.$ in both cases $)$ with $0.1 \mathrm{M}$ $\mathrm{NaOH}$ allowed the determination of their average degrees of acetylation and substitution. These titrations were carried out in a glass cell thermostated at $25^{\circ} \mathrm{C} \pm 0.4{ }^{\circ} \mathrm{C}$ and under nitrogen bubbling. An automatic titrator (Schott Titronic Universal) with accuracy of $0.05 \mathrm{~mL}$ was employed and simultaneous measurements of the solution's conductivity and $\mathrm{pH}$ were carried out upon the addition of the $\mathrm{NaOH}$ solution. The Handylab LF1 conductivimeter and the CG 843P pHmeter, both from Schott-Geräte, were used in these experiments.

The average degree of acetylation $(\overline{D A})$ was calculated by using equations 1 and 2 :

$$
\begin{aligned}
& \% \overline{D D}=\left(\mathrm{M} \mathrm{x}\left[\mathrm{v}_{3}-\mathrm{v}_{2}\right] \times[\mathrm{NaOH}] / \mathrm{m}\right) \times 100 \\
& \% \overline{D A}=100-\% \overline{D D}
\end{aligned}
$$

where: $\overline{D D}$ is the average degree of deacetylation; $\overline{D A}$ is the average degree of acetylation; $\mathrm{M}$ is the average molar mass of repetitive unit; $\mathrm{v}_{2}$ is the volume of base added to reach the second inflexion point; $v_{3}$ is the volume of base added to reach the third inflexion point; $[\mathrm{NaOH}]$ is the concentration of $\mathrm{NaOH}(\mathrm{mol} / \mathrm{L}) ; \mathrm{m}$ is the mass of the sample contained in the aliquot of $100 \mathrm{~mL}$.

The degrees of substitution of the carboxymethylchitosan were calculated with the equation 3 :

$\overline{D S}=\mathrm{M} \times\left([\mathrm{NaOH}] \times\left[\mathrm{v}_{2}-\mathrm{v}_{1}\right]\right) / \mathrm{m}-\left(80 \times[\mathrm{NaOH}] \times\left[\mathrm{v}_{2}-\mathrm{v}_{1}\right]\right)(3)$

where: $\overline{D S}$ is the degree of substitution; $\mathrm{M}$ is the average molar mass of repetitive unit of chitosan; $[\mathrm{NaOH}]$ is the concentration of $\mathrm{NaOH}(\mathrm{mol} / \mathrm{L}), \mathrm{v}_{1}$ is the volume of base added to reach the first inflexion point; $v_{2}$ is the volume of base added to reach the second inflexion point; $m$ is the mass of carboxymethylchitosan contained in the aliquot of $100 \mathrm{~mL}$.

\section{Results and Discussion}

Although the works in the literature report that the carboxymethylation of chitosan occurs selectively according 
to the conditions used in the reaction ${ }^{[13,14]}$, a complex mixture of products is generally obtained when ordinary conditions are used. In fact, the carboxymethylation reaction of chitosan may introduce carboxymethyl groups in the hydroxyl groups bonded to the carbon atoms 3- and 6- of the glucopyranose unit. The amino group is also a reactive site and two carboxymethyl groups can be introduced. As the reaction is not generally complete, some units of glucosamine as well as acetylglucosamine units coming from the partial deacetylation of chitin may also occur. It is also necessary to take into account the combinations that can occur involving the presence of carboxymethyl groups in the different structural units and then at least 12 different units should be considered to compose the chains of carboxymethylchitosan. Thus, the complete characterization of this derivative of chitosan may present difficulties due to its structural complexity.

The ${ }^{1} \mathrm{H}$ NMR spectrum of chitosan (sample Q) is shown in Figure 2 . The signal centered at $\delta \cong 2.00 \mathrm{ppm}$ corresponds to the hydrogens of the methyl moieties belonging to the acetamido groups. The signal observed between 3.10 and 2.90 $\mathrm{ppm}$ corresponds to the hydrogen bonded to the $\mathrm{C} 2$ glucosamine ring, while the signals between 3.30 and 4.00

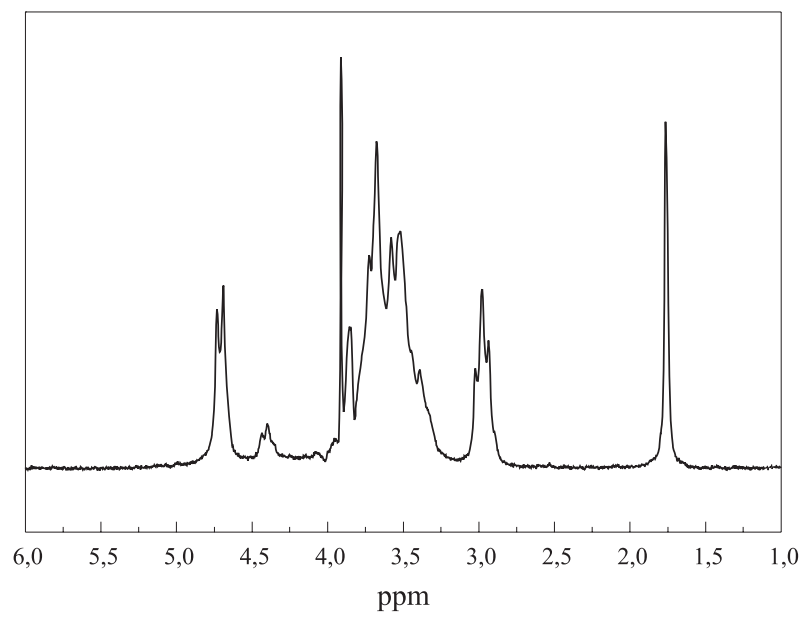

Figure 2. ${ }^{1} \mathrm{H}$ NMR spectrum of chitosan (sample Q) in $\mathrm{D}_{2} \mathrm{O} / \mathrm{HCl}(1: 1 \mathrm{v} / \mathrm{v})$ at $80^{\circ} \mathrm{C}$.

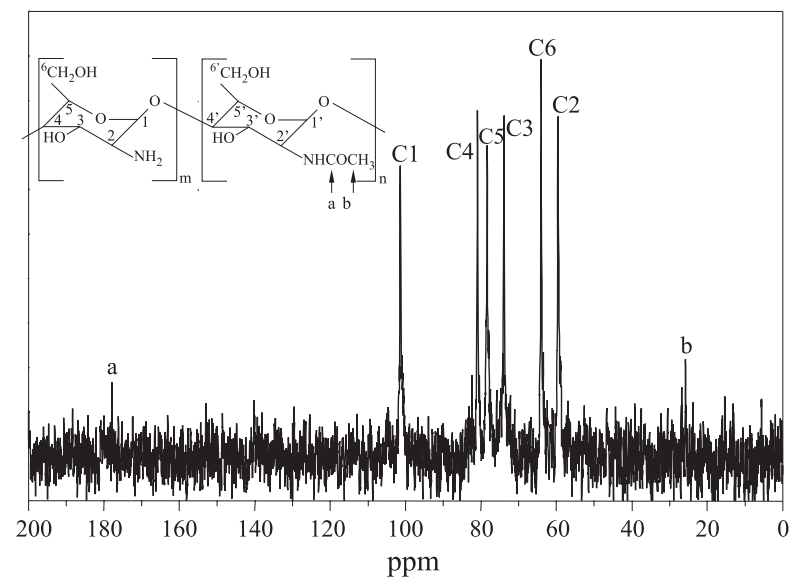

Figure 3. ${ }^{13} \mathrm{C}$ NMRspectrum of chitosan (sample Q) in $\mathrm{D}_{2} \mathrm{O} / \mathrm{HCl}(1: 1 \mathrm{v} / \mathrm{v})$ at $80^{\circ} \mathrm{C}$. ppm correspond to hydrogens bonded to the carbon atoms $\mathrm{C} 3, \mathrm{C} 4, \mathrm{C} 5$ and $\mathrm{C} 6$ of the glucopyranose that are overlaped. The hydrogen bonded to the anomeric carbon $(\mathrm{C} 1)$ gives rise to the the signals in the range $4.40<\delta<5.00$.

The ${ }^{13} \mathrm{C}$ NMR of chitosan (sample Q, Figure 3 ) shows signals at $177.9 \mathrm{ppm}$ and at $25 \mathrm{ppm}$, which are assigned to the carbonyl carbon of $-\mathrm{COCH}_{3}$ and the methyl carbon $\left(-\mathrm{CH}_{3}\right)$, respectively. These signals are less intense than the other signals, even though the average degree of acetylation of the sample is not small ( $\overline{\mathrm{DA}} \cong 25)$. Indeed, the different carbons have very different relaxation times and the acquisition of spectrum was not optimized to allow a quantitative analysis. The signal at $101.3 \mathrm{ppm}$ is assigned to the hydrogen bonded to carbon $\mathrm{C} 1$ of chitosan and the signals in $59.6 \mathrm{ppm}, 73.1$ ppm, $81.1 \mathrm{ppm}, 78.6 \mathrm{ppm}$ and $64 \mathrm{ppm}$ are assigned to carbons C2, C3, C4, C5 and C6 of glypyranose (Figure 3), respectively.

The structural modifications introduced by the carboxymethylation can be observed by comparing the ${ }^{1} \mathrm{H}$ NMR spectrum of chitosan (Figure 2) to that of the sample $\mathrm{QC}_{7}$ (Figure 4). Indeed, this latter is considerably different and more complex than that of the parent chitosan. The occurrence of $\mathrm{N}$-carboxymethylation is denoted by the signals in the

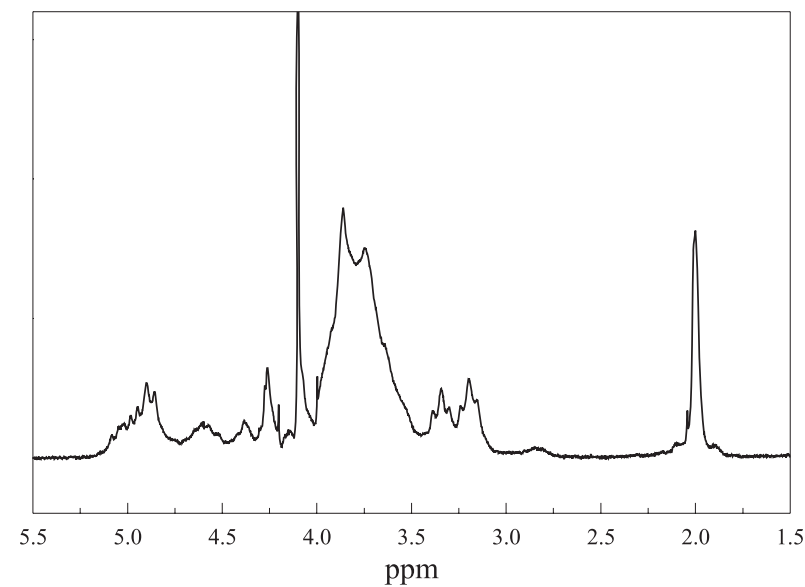

Figure 4. ${ }^{1} \mathrm{H}$ NMR spectrum of carboxymethylchitosan (sample $\mathrm{QC}_{7}$ ) in $\mathrm{D}_{2} \mathrm{O} / \mathrm{HCl}(1: 1 \mathrm{v} / \mathrm{v})$ at $80{ }^{\circ} \mathrm{C}$.

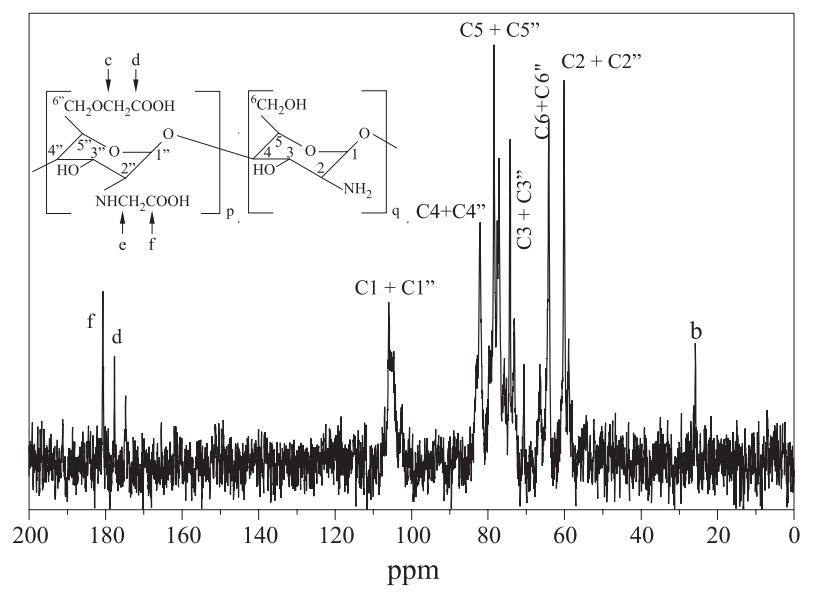

Figure 5. ${ }^{13} \mathrm{C}$ NMR spectrum of carboxymethylchitosan (sample $\mathrm{QC}_{7}$ ) in $\mathrm{D}_{2} \mathrm{O} / \mathrm{HCl}(1: 1 \mathrm{v} / \mathrm{v})$ at $80^{\circ} \mathrm{C}$. 
range $3.1-3.4 \mathrm{ppm}$ (Figure 4) which are assigned, according to Muzzarelli et al. ${ }^{[16]}$, to mono and dissubstitution of the amino groups. However, it is not possible to determine whether carboxymethylation occurred in all the amino groups because the signal of hydrogen bonded to $\mathrm{C} 2$ overlaps the signals assigned to $\mathrm{N}$-carboxymethyl sites.

The ${ }^{13} \mathrm{C}$ NMR spectra of chitosan (sample Q) and carboxymethylchitosan (sample $\mathrm{QC}_{7}$ ) are shown in figures 3 and 5, respectively. In the spectrum of carboxymethylchitosan (Figure 5), the signals due to $\mathrm{C} 1$ and $\mathrm{C} 1$ " carbons are shifted from $101.3 \mathrm{ppm}$ (signal assigned to $\mathrm{C} 1$ carbon in chitosan) to $105.9 \mathrm{ppm}$ because of the electron-withdrawing effect of the carboxymethyl substituents. Since various different units occur in the structure of carboxymethylchitosan, many of the signals in the spectrum of chitosan appear split in the spectrum of carboxymethylchitosan. Thus, the signals at $60.1 \mathrm{ppm}$ (C2+C2"), $73.8 \mathrm{ppm}$ (C3), $73.2 \mathrm{ppm}(\mathrm{C} 3$ "), $82.2 \mathrm{ppm}$ (C4+C4"), $78.2 \mathrm{ppm}(\mathrm{C} 5+\mathrm{C} 5 ")$ and 63.9ppm (C6+C6") are split and shifted in relation to those detected in the spectrum of the parent chitosan.

The signals due to $\mathrm{C} 3$ and $\mathrm{C} 6$ are also split in the spectrum of carboxymethylchitosan (Figure 5), probably as a consequence of the carboxymethylation of the hydroxyl groups bonded to $\mathrm{C} 3$ and $\mathrm{C} 6$. According to the literature ${ }^{[17]}$, the signal observed at $180.7 \mathrm{ppm}$ is assigned to the carbonyl carbons of carboxymethyl groups ( $\mathrm{d}$ and f) while the one detected at 177.9 ppm corresponds to the carbonyl carbon of $-\mathrm{COCH}_{3}$ of the parent chitosan. The methylene groups $\left(-\mathrm{CH}_{2}\right)$, carbons e and $\mathrm{c}$, give rise to the signals at 53 and $57.4 \mathrm{ppm}$, respectively. However, no signal was detected at $53 \mathrm{ppm}$ in the spectrum of carboxymethylchitosan (Figure 5) and the weak signal at 58.4 ppm can be probably assigned to the methylene $\left(-\mathrm{CH}_{2}\right)$ bonded to the amino group(-NH). These features are taken as evidence that the carboxymethylation occurred at the hydroxyl as well as in the amino groups of chitosan.

The titration curves of chitosan (sample Q, Figure 6a) and carboxymethylchitosan (sample $\mathrm{QC}_{7}$, Figure 6b) were used to determine the average values of the degrees of acetylation $(\overline{D A})$ and substitution $(\overline{D S})$. The condutimetric curve of carboxymethylchitosan (sample $\mathrm{QC}_{7}$, Figure $6 \mathrm{~b}$ ) shows a different profile from that of the chitosan's curve (Figure 6a), mainly in the neighborhood of the equivalence point. Indeed, the titration of carboxymethylchitosan presents more complex features due to the presence of different acid groups that possess similar acidity constants. Thus, the condutimetric titration curve of the carboxymethyled sample (Figure $6 \mathrm{~b}$ ) is curved in the range $3.70-6.40 \mathrm{~mL}$, making it difficult to determine the equivalence point. The first linear branch of the curve, corresponding to the interval from $\mathrm{v}=0.00 \mathrm{ml}$ to $\mathrm{v}$ $=\mathrm{v}_{1}=3.70 \mathrm{~mL}$ corresponds to the volume of base added for the neutralization of the stronger acid $\left(\mathrm{H}_{3} \mathrm{O}^{+}\right)$present in the solution. The second equivalence point is achieved when $\mathrm{v}=\mathrm{v}_{2}=6.40 \mathrm{~mL}$ and the difference $\mathrm{v}_{2}-\mathrm{v}_{1}$ is the volume of base necessary to neutralize the carboxymethyl groups $\left(-\mathrm{CH}_{2} \mathrm{COOH}\right)$. The third equivalence point is achieved when $\mathrm{v}=\mathrm{v}_{3}=9.70 \mathrm{~mL}$ and the difference $\mathrm{v}_{3}-\mathrm{v}_{2}$ is the volume of

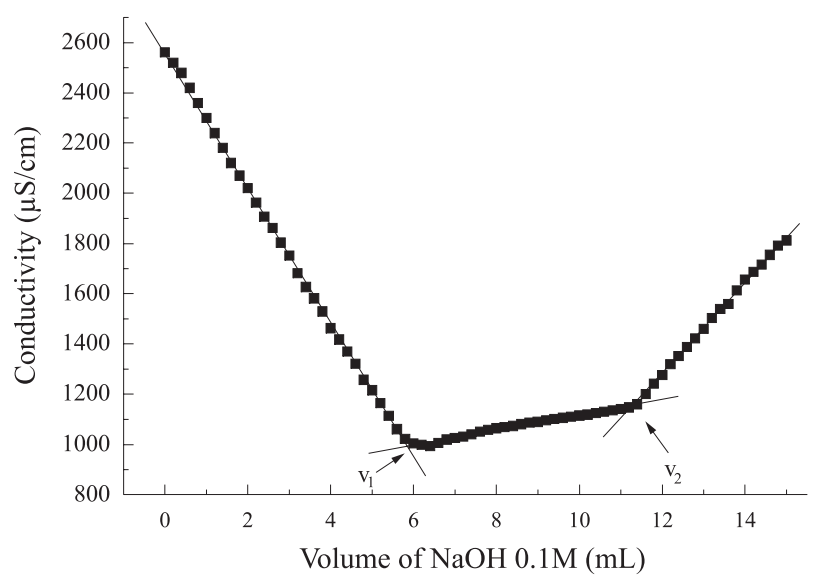

Figure 6a. Condutimetric titration curve of chitosan (sample Q) (a).

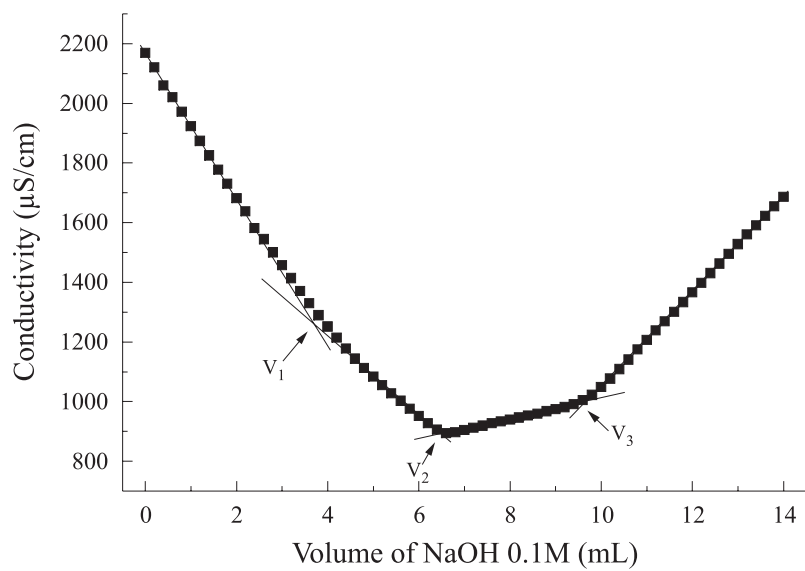

Figure 6b. Condutimetric titration curve of carboxymethylchitosan (sample $\left.\mathrm{QC}_{7}\right)(\mathrm{b})$.

base necessary to neutralize the ammonium groups $\left(-\mathrm{NH}_{3}{ }^{+}\right.$, ${ }^{+} \mathrm{NH}_{2} \mathrm{R},{ }^{+} \mathrm{NHR}_{2}$, where $\left.\mathrm{R}=-\mathrm{CH}_{2} \mathrm{COOH}\right)$. The fourth linear branch of the curve indicates the presence of an excess of strong electrolyte $(\mathrm{NaOH})$. The values of the equivalent volumes obtained from the titration curves were used to calculate of the average degrees of acetylation $(\overline{D A})$ and substitution $(\overline{D S})$ (Table 1$)$.

The values of $\overline{D S}$ of the samples $\mathrm{QC}_{3}, \mathrm{QC}_{5}, \mathrm{QC}_{7}$ and $\mathrm{QC}_{10}$ (Table 1) are quite similar, indicating that for a reaction time from 3 to 10 hours the carboxymethylated efficiency is not

Table 1. Values of $\overline{D S}$ and $\overline{D A}$ of chitosan and carboxymethylchitosans determined by conductivity(a) and $\mathrm{pH}(\mathrm{b})$ titrations.

\begin{tabular}{lcccc}
\hline \multicolumn{1}{c}{ Sample } & $\overline{\overline{\boldsymbol{S}}}(\mathbf{a})$ & $\overline{\boldsymbol{D S}}(\mathbf{b})$ & $\overline{\overline{\boldsymbol{A A}}}(\mathbf{a})$ & $\overline{\overline{\boldsymbol{A A}}}(\mathbf{b})$ \\
\hline Q & - & - & 24 & 24.6 \\
QC3 & 0.69 & 0.69 & 41.2 & 45.2 \\
QC5 & 0.74 & 0.74 & 43.8 & 43.2 \\
QC7 & 0.60 & 0.77 & 48.3 & 52.6 \\
QC10 & 0.52 & 0.56 & 46.8 & 44.8 \\
QC7E & 0.80 & 0.71 & 49.7 & 50.5 \\
QC10E & 1.44 & 1.36 & 44.4 & 46.0 \\
\hline
\end{tabular}


alterated significantly changed. This probably occurred because for progressively longer times the monochloroacetic acid concentration was reduced as it preferentially reacted with the sodium hydroxide that was present in a very large excess. However, more substituted samples $\left(\mathrm{QC}_{7 \mathrm{E}}\right.$ and $\left.\mathrm{QC}_{10 \mathrm{E}}\right)$ were obtained when the reaction was carried out in the presence of a higher excess of monochloroacetic acid. Also, the $\overline{D A}$ of carboxymethylated derivatives are higher than that of the parent chitosan, confirming that the amino groups were also carboxymethylated, as indicated by ${ }^{1} \mathrm{H}$ and ${ }^{13} \mathrm{C}$ NMR spectroscopy.

\section{Conclusions}

The characterization of carboxymethylchitosan was difficult due to its structural complexity. Indeed, the ${ }^{1} \mathrm{H}$ NMR and ${ }^{13} \mathrm{C}$ NMR spectra and the titrations of the samples prepared in this work showed the occurrence of $\mathrm{O}$ - and N-carboxymethylation in all cases. The degrees of substitution were not proportionally increased when the reaction proceeded for longer times but the use of a higher excess of monochloroacetic acid resulted in more substituted samples.

Such results show that the structural characteristics of carboxymethylchitosan are strongly affected by the stoichiometry of the reaction and that other variables, such as the reaction temperature, should be studied aiming to reduce the occurrence of $\mathrm{N}$-carboxymethylation.

\section{Acknowledgment}

The authors are grateful to FAPESP and CNPq for the financial support, and to NMR Laboratory of UFSCar, Brazil, for the ${ }^{1} \mathrm{H}$ NMR analysis.

\section{References}

1. Abram, P. A.; Higuera, I. - "Generalidades", in: Quitina y Quitosano: obtention, caracterizacion y aplicaciones, cap.1, Ana Pastor de Abram (ed), Fondo Editorial., Pontificia Universidad Católica del Perú (2004).

2. Signini, R. - "Estudo das relações estrutura/propriedades de quitina e quitosana”, Tese de Doutorado, Universidade de São Paulo, Brasil (2002).
3. Kittur, F. S.; Prashanth, K. V .H.; Sankar, K. U.; Tharanathan, R. N. - Carbohyd. Polym., 49, p.185 (2002).

4. Britto, D.; Campana-Filho, S. P. - Polym. Degrad. Stab., 84, p.353 (2004).

5. Zhao, L.; Mitomo, H.; Nagasawa, N.; Yoshii, F.; Kume, T. Carbohyd. Polym., 51, p.169 (2003).

6. Chen, L.; Du, Y.; Zeng, X. - Carbohyd. Res., 338, p.333 (2003).

7. Muzzarelli, R.A.A.; Muzzarelli, C.; Tarsi, R.; Miliani, M.; Garbbanelli, F.; Cartolari, M. - Biomacromol., 2, p.165 (2001).

8. Liu, X.F.; Guan, Y.L.; Yang, D.Z.; Li, Z.; Yao, K.D. - J. Appl. Polymer. Sci., 79, p.1324 (2001).

9. Rhazi, M.; Desbrières, J.; Tolaimate, A; Rinaudo, M.; Vottero, P.; Alagui, A.; El Meray, M. - Europ. Polym. J., 38, p.1523 (2002).

10. Abreu, F.R. - "Estudos de obtenção de carboximetilquitosanas e derivados entrecruzados e de sua interação com ions metálicos”, Tese de Mestrado, Universidade de São Paulo, Brasil (2002)

11. Zhao, X.; Kato, K.; Fukumoto, Y.; Nakamae, K. - Int. J. Adhes. \& Adhesiv., 21, p.227 (2001).

12. Rhazi, M.; Desbriéres, J.; Tolaimate, A; Rinaudo, M.; Vottero, P.; Alagui, A; El Meray, M. - Europ. Polym. J., 38, p.1523 (2002).

13. Campana-Filho, S. P.; Desbrières, J. Chitin, Chitosan and Derivatives, in: Natural Polymers and Agrofibers Composites, 41-71, E. Frollini, A. L. Leão, L.H.C Mattoso eds. USP, UNESP, EMBRAPA, (2000).

14. Muzzarelli, R. A. A. - Carbohydr. Polym., 8, p.1 (1988).

15. Caraschi, J. C. - "Estudos das Relações estrutura/ propriedades de carboximetilcelulose obtida por derivatização de polpa de bagaço de cana-de-açucar”, Tese de Doutorado, Universidade de São Paulo, Brasil (1997).

16. Muzzarelli, R. A. A.; Ilari, P.; Petraluro, M. - Int. J. Biol. Macromol., 16, p.177 (1994).

17. Zhao, Z.; Wang, Z.; Wang, N. S.- Desalination, 144, 35-39 (2002). 